\title{
The Prevalence of Obstructive Airway Disease by Spirometric Indices in Nonsmoker Patients with Catheter-Diagnosed Coronary Artery Disease
}

\author{
Ankur Agrawal, Saurabh Kumar Singh, Prahlad P. Prabhudesai ${ }^{1}$ \\ Department of Pulmonary Medicine, Gajra Raja Medical College and Jayarogya Group of Hospitals, Gwalior, Madhya Pradesh, 'Lilavati Hospital and Research Centre, \\ Mumbai, Maharashtra, India
}

\section{Abstract}

Aim: The aim of this study was to assess the prevalence of obstructive airway disease (OAD) in coronary artery disease (CAD) patient's using spirometric indices. Patients and Methods: The prospective study was conducted between June 2014 and June 2015. Patients admitted to the intensive coronary care unit having a proven diagnosis of CAD (single or multiple vessel disease) on coronary angiography were undergone spirometry examination. Results: This study included a total of 80 patients of proven CAD. Sixty-one patients were male and 19 were female. The mean age of the cases was 59.29 years. In our study, 37.5\% had triple-vessel disease, 33.8\% had double-vessel disease, and remaining $28.8 \%$ had single-vessel disease. Eighteen patients (22.5\%) were found to have OAD. On comparison of severity of OAD with the severity of $\mathrm{CAD}$, no statistically significant association was found. Conclusion: It is imperative to carry out inexpensive investigations such as spirometry in all the patients with CAD so that both the conditions can be managed adequately with better outcomes.

Keywords: Coronary angiography, coronary artery disease, obstructive airway diseases, spirometry

\section{INTRODUCTION}

Asthma and chronic obstructive pulmonary disease (COPD) are collectively known as obstructive airway disease (OAD). Major risk factors for the development of OADs are smoking, occupational exposures, and exposure to air pollutant. ${ }^{[1]}$ COPD is characterized by a nonreversible obstructive ventilatory pattern on spirometry. It is usually found in smokers and can lead to respiratory failure. Coronary artery disease (CAD) (atherosclerotic heart disease/ischemic heart disease [IHD]) results from the accumulation of atheromatous plaques within the walls of the coronary arteries hampering the supply of oxygen and nutrients to the myocardium. ${ }^{[2]}$

Both IHD and COPD share smoking as a common risk factor. Both are systemic disorders with shared mechanism and pathophysiologic processes. ${ }^{[2]}$ The kinship between COPD and CAD is not a simple presence of the same disease but far more complicated. Prevalence of both the diseases is also on the rise because of increase in the age of the population, increase in awareness about COPD, and better

\begin{tabular}{|l|l|}
\hline \multicolumn{2}{|c|}{ Access this article online } \\
\hline Quick Response Code: & Website: \\
\hline & www.ijrconline.org \\
\cline { 2 - 2 } & \\
\hline
\end{tabular}

availability of the diagnostic tests. Both diseases are major causes of morbidity and mortality worldwide. ${ }^{[3]}$ COPD has been projected to be the third leading cause of death by the year 2020. The Global Burden of Disease project estimates that COPD causes the death of at least 2.9 million people annually. Many studies had shown that patients with COPD are at two to three times greater risk for cardiovascular mortality accounting for $50 \%$ of the total deaths. ${ }^{[2]}$ The PREMIER Registry reported the prevalence of COPD as high as $15.6 \%$ in patients with myocardial infarction (MI). They have concluded that patients with COPD have greater mortality, higher hospitalization rates, and poorer health status even 1 year following an episode of MI. ${ }^{[4]}$ Although additional research is needed, clinicians should recognize

Address for correspondence: Dr. Saurabh Kumar Singh, Department of Pulmonary Medicine, Gajra Raja Medical College and Jayarogya Group of Hospitals, Gwalior, Madhya Pradesh, India. E-mail: doctorsaurabhsingh@gmail.com

This is an open access journal, and articles are distributed under the terms of the Creative Commons Attribution-NonCommercial-ShareAlike 4.0 License, which allows others to remix, tweak, and build upon the work non-commercially, as long as appropriate credit is given and the new creations are licensed under the identical terms.

For reprints contact: reprints@medknow.com

How to cite this article: Agrawal A, Singh SK, Prabhudesai PP. The prevalence of obstructive airway disease by spirometric indices in nonsmoker patients with catheter-diagnosed coronary artery disease. Indian J Respir Care 2019;8:46-50. 
Agrawal, et al.: COPD in coronary artery disease patients

that patients with COPD are at high risk of poor outcomes after MI.

In another study, ${ }^{[5]}$ in 1980 s, a secondary prevention study with nifedipine (SPRINT) was conducted in Israel among 2276 survivors of acute MI. It was conducted at various centers that reported the prevalence of $7 \%$ COPD in MI patients. They found that the patients with COPD had longer duration of hospital stay and the postdischarge mortality rate was also high, laying the emphasis that the COPD diagnosis may affect the posttreatment course of MI patients.

This study was done to evaluate the prevalence of OAD in nonsmoker individuals diagnosed with $\mathrm{CAD}$, based on the spirometric indices.

\section{Patients and Methods}

The cross-sectional observational study was carried out in the department of pulmonary medicine, at our tertiary health-care center. The cross-sectional observational study was done in the time frame of July 2014 to June 2015.

A total of 80 patients admitted in the coronary care unit who were diagnosed to have $\mathrm{CAD}$ on coronary angiography, within the mentioned time period were recruited in the study. Sample size for this study was calculated by sample size calculator and sampling spreadsheet Excel files by the World Health Organization for chronic diseases and health promotion and was rounded up to 80 cases.

\section{Inclusion criteria}

1. Patients admitted in Intensive Coronary Care Unit with a proven diagnosis of CAD (single-disease or multivessel disease) on coronary angiography

2. Age $>30$ years and $\leq 70$ years.

\section{Exclusion criteria}

1. Patients who are current smokers or have a history of smoking/chulha smoke exposure

2. Patients who are known cases of obstructive lung disease and/or restrictive lung disease

3. Patients who are already on steroids or bronchodilators

4. Patients who are admitted with symptoms suggestive of CAD but are found to have a normal coronary angiogram (CAG)

5. Patients with congestive heart failure

6. Patients with secondary hypertension

7. Gravely ill patients or patients requiring mechanical ventilation

8. Patients with psychiatric disorder

9. Unwilling and uncooperative patients.

Written informed consent on a prescribed format was obtained from the patients enrolled in the study. They were interviewed in detail and general and physical examination was done. Anthropometric measurements such as age, sex, height, weight, and body mass index (BMI) were noted. Detailed enquiry was made regarding the presence of comorbidities and their current ongoing medications. Smoking history was also taken in detail and those with a positive history were excluded from the study.

All the patients were subjected to bedside spirometry after stabilization with a MIR Spirolab III Spirometer (a turbine-based spirometer) in accordance with the American Thoracic Society (ATS)/European Respiratory Society (ERS) guidelines. Ratio of forced expiratory volume in $1 \mathrm{~s}$ and forced vital capacity (FEV1/FVC) $\leq 70 \%$ was used to make a diagnosis of OAD.

Before the test, the patient was made to sit comfortably and the whole procedure was explained to them in the language they understand best. Nose clips were used to prevent any false readings. At least three maneuvers meeting the reproducibility and acceptability criteria (as per the ATS/ERS guidelines) were noted.

The findings of spirometry were categorized as normal or mild/moderate/severe/very severe airflow obstruction depending on the values of FEV1 and FVC and FEV1/FVC ratio as per the Global Initiative for COPD.

\section{Statistical test used}

Qualitative data are represented in the form of frequency and percentage. Association between qualitative variables was assessed by Chi-Square test, with a continuity correction for all $2 \times 2$ tables and by Fisher's exact test for all $2 \times 2$ tables, where Chi-Square test was not valid due to small counts. In the presence of small counts in tables with more than two rows, adjacent row data were pooled and Chi-square test reapplied. Comparison of various variables by GOLD staging status among cases was done using one-way ANOVA if data passed "normality test" or by Kruskal-Wallis one-way analysis of variance on ranks test, where variables failed "normality test" (e.g., comparison of age [years] by GOLD staging status of no $\mathrm{OAD}$, mild $\mathrm{OAD}$, moderate $\mathrm{OAD}$, severe $\mathrm{OAD}$, and very severe OAD). Appropriate statistical software, including but not restricted to Microsoft Excel, SPSS 16, IBM, Armonk, NY, United States of America was used for statistical analysis.

\section{RESULTS}

A total of 80 patients with a diagnosis of CAD on CAG, satisfying the inclusion and exclusion criteria, were enrolled in the study. All of them were subjected to spirometry.

Out of these 80 patients, 61 were male (76.3\%) and 19 patients were female $(23.8 \%)$. Mean age was 59.29 years with a standard deviation of 7.95 (range: $38-70$ years). About 55\% of the cases were working and $45 \%$ were nonworking. All of them were never smokers and had no history of chulha smoke exposure. Of the total number of cases, $13(16.3 \%)$ had normal BMI, that is, $18-24.9 \mathrm{~kg} / \mathrm{m}^{2} ; 32(40 \%)$ patients were overweight, that is, BMI $25-29.9 \mathrm{~kg} / \mathrm{m}^{2}$; and 35 patients were obese (43.8\%), that is, BMI $>30 \mathrm{~kg} / \mathrm{m}^{2}$. Mean BMI was $29.24 \pm 4.08 \mathrm{~kg} / \mathrm{m}^{2}$ (range: $19.20-38.4$ ). 
Agrawal, et al.: COPD in coronary artery disease patients

Among the cases, $28.8 \%$ had single-vessel disease (SVD), $33.8 \%$ had double-vessel disease (DVD), and 37.5\% patients had triple-vessel disease (TVD) [Table 1]. Mean postbronchodilator FEV1 was $0.76 \pm 0.151$. Association between OAD and vessel involvement [Table 2] showed $21.7 \%$ patients with SVD, $11.1 \%$ with DVD, and $33.3 \%$ of TVD patients had OAD. This association was not found to be significant $(P>0.05)$. Association between the severity of OAD on the basis of GOLD staging and severity of vessel involvement was also nonsignificant $(P>0.05)$ [Table 3]. However, there was a significant relationship between the female sex and OAD in the IHD cases [Table 4].

\section{Discussion}

In India, the overall prevalence of COPD was found to be $5 \%$ in male and $2.7 \%$ in female population with a median male-to-female ratio of 1.6:1. ${ }^{[6]}$ According to a recent systematic review from major studies in India, the prevalence of COPD seems to range between $6.5 \%$ and $7.7 \%$ in rural and up to $9.9 \%$ in urban India. ${ }^{[7]}$

In our study, we found that the prevalence of OAD in patients with $\mathrm{CAD}$ was $22.5 \%$. This was higher in comparison to the general population. Increased inflammation may be the reason for increased prevalence of COPD in CAD.$^{[8]}$ All the patients had no history of exposure to the first-hand tobacco smoke or to the environmental tobacco smoke. As exposure to tobacco smoke is a risk factor for both the conditions, we have excluded the possible confounding factor. Various studies done in India and abroad showed the prevalence of OAD in patients with CAD ranging from $4.7 \%$ to as high as $60 \%$ and that airflow limitation is an independent risk factor for cardiovascular disease, particularly CAD.$^{[9-12]}$ All the cases in our study were subjected to spirometry in accordance with the ATS/ERS guidelines, and the severity of airflow obstruction was determined using the GOLD criteria. In another study, Engstrom et al. ${ }^{[13]}$ in 467 hypertensive men found out that the incidence of cardiovascular disease associated with hypertension is increased among men with reduced lung function.

In one of the Indian studies, it was suggested that IHD and hypertension should undergo routine inexpensive investigations such as spirometry to detect the presence of underlying OAD. They found the prevalence of $18 \%$ among the patients of IHD and hypertension ${ }^{[1]}$ as compared to $2 \%$ in controls. Das et al. showed the prevalence of $51.2 \%$ of COPD in IHD patients according to the GOLD criteria. Most of the cases had COPD of moderate-to-severe degree. They found the positive correlation between the severity of COPD and impaired left ventricular functions. ${ }^{[14]}$ Furthermore, Soriano et al. ${ }^{[15]}$ showed that the prevalence of airflow limitation was $33.6 \%$ in patients with $\mathrm{CAD}$ and that $60 \%$ of those with spirometrically confirmed airflow limitation did not receive any respiratory treatment. Bursi et al.${ }^{[9]}$ in their study of 3438 patients with MI concluded that the prevalence of COPD in these patients was $12 \%$ and was associated with a markedly increased risk of death after

\begin{tabular}{lc}
\hline Table 1: Characteristics of patients & \\
\hline Patients characteristics & Number of patients (\%) \\
\hline Gender & $19(23.8)$ \\
Female & $61(76.3)$ \\
Male & \\
Age distribution (years) & $5(6.3)$ \\
$35-44$ & $17(21.3)$ \\
$45-54$ & $33(41.3)$ \\
$55-64$ & $25(31.3)$ \\
65-74 & \\
BMI & $35(43.8)$ \\
Obese & $32(40.0)$ \\
Overweight & $13(16.2)$ \\
Normal & \\
Vessel involved & $23(28.8)$ \\
Single-vessel disease & $27(33.8)$ \\
Double-vessel disease & $30(37.5)$ \\
Triple-vessel disease & \\
Distribution of obstructive airway disease & $62(77.5)$ \\
No OAD & $4(5.0)$ \\
Mild OAD & $9(11.3)$ \\
Moderate OAD & $4(5.0)$ \\
Severe OAD & $1(1.3)$ \\
Very severe OAD & \\
Reversibility on spirometry & $10(12.5)$ \\
Yes & $70(87.5)$ \\
No &
\end{tabular}

BMI: Body mass index, OAD: Obstructive airway disease

Table 2: Association among the cases between obstructive airway disease and vessels involved

\begin{tabular}{|c|c|c|c|c|c|}
\hline \multirow[t]{2}{*}{ OAD } & & \multicolumn{3}{|c|}{ Vessels involved, $n(\%)$} & \multirow[t]{2}{*}{ Total } \\
\hline & & SVD & DVD & TVD & \\
\hline Yes & & $5(21.7)$ & $3(11.1)$ & $10(33.3)$ & $18(22.5)$ \\
\hline No & & $18(78.3)$ & $24(88.9)$ & $20(66.7)$ & $62(77.5)$ \\
\hline Total & & $23(100.0)$ & $27(100.0)$ & $30(100.0)$ & $80(100.0)$ \\
\hline$\chi^{2}$ & Value & df & $P$ & \multicolumn{2}{|c|}{ Association is } \\
\hline Pearson $\chi^{2}$ & 4.035 & 2 & 0.133 & \multicolumn{2}{|c|}{ Not significant } \\
\hline
\end{tabular}

SVD: Single-vessel disease, DVD: Double-vessel disease,

TVD: Triple-vessel disease, OAD: Obstructive airway diseases

MI independently of age, risk factors, and comorbidities. This study emphasizes the importance of OAD and the need for increase care for these high-risk patients.

A study done by Almagro et al. ${ }^{[16]}$ in 133 patients of IHD confirmed with percutaneous coronary intervention and concluded that the prevalence of COPD ( $24.8 \%$ in this study) and underdiagnoses $(81.8 \%$ in this study) are both high and that these patients are older and have more number of coronary vessels involved. Similarly, in another study from China also showed that COPD was associated with multivessel involvement. ${ }^{[8]}$ While Ahmad et al..$^{[17]}$ found $73 \%$ of patients with COPD and CAD had single-vessel disease, whereas $66 \%$ of non-COPD CAD patients had multivessel disease. This is in 
Agrawal, et al.: COPD in coronary artery disease patients

\begin{tabular}{|c|c|c|c|c|}
\hline \multirow[t]{2}{*}{ GOLD staging } & \multicolumn{3}{|c|}{ Vessels involved, $\boldsymbol{n}(\%)$} & \multirow[t]{2}{*}{ Total } \\
\hline & SVD & DVD & TVD & \\
\hline No OAD & $18(78.3)$ & $24(88.9)$ & $20(66.7)$ & $62(77.5)$ \\
\hline Mild $\mathrm{OAD}^{\wedge}$ & $1(4.3)$ & $1(3.7)$ & $2(6.7)$ & $4(5.0)$ \\
\hline Moderate $\mathrm{OAD}^{\wedge}$ & $4(17.4)$ & $2(7.4)$ & $3(10.0)$ & $9(11.3)$ \\
\hline Severe $\mathrm{OAD}^{\wedge}$ & $0(0.0)$ & $0(0.0)$ & $4(13.3)$ & $4(5.0)$ \\
\hline Very Severe OAD & $0(0.0)$ & $0(0.0)$ & $1(3.3)$ & $1(1.3)$ \\
\hline Total & $23(100.0)$ & $27(100.0)$ & $30(100.0)$ & $80(100.0)$ \\
\hline Value & df & $P$ & \multicolumn{2}{|c|}{ Association is } \\
\hline Pearson $\chi^{2 s} \quad 10.685$ & 8 & 0.220 & \multicolumn{2}{|c|}{ Not significant } \\
\hline Pearson $\chi^{2^{\wedge}} \quad 4.035$ & 2 & 0.133 & \multicolumn{2}{|c|}{ Not significant } \\
\hline \multicolumn{5}{|c|}{$\begin{array}{l}\$ 12 \text { cells }(80.0 \%) \text { have expected count }<5 .{ }^{\wedge} \text { Row data pooled and } \\
\text { Chi-square test reapplied. OAD: Obstructive airway disease, } \\
\text { SVD: Single-vessel disease, DVD: Double-vessel disease, } \\
\text { TVD: Triple-vessel disease, GOLD: Global Initiative for Chronic } \\
\text { Obstructive Lung Disease }\end{array}$} \\
\hline
\end{tabular}

\begin{tabular}{|c|c|c|c|c|}
\hline \multirow[t]{2}{*}{ Gender } & & \multicolumn{2}{|c|}{ OAD } & \multirow[t]{2}{*}{ Total } \\
\hline & & Yes & No & \\
\hline Female & & $9(47.4)$ & $10(52.6)$ & $19(100.0)$ \\
\hline Male & & $9(14.8)$ & $52(85.2)$ & $61(100.0)$ \\
\hline Total & & $18(22.5)$ & $62(77.5)$ & $80(100.0)$ \\
\hline$\chi^{2}$ & Value & df & $P$ & Association is \\
\hline Pearson $\chi^{2 s}$ & 8.837 & 1 & 0.00295 & Significant \\
\hline $\begin{array}{l}\text { Continuity } \\
\text { corrections }\end{array}$ & 7.066 & 1 & 0.00786 & Significant \\
\hline Fisher's exact test & & & 0.00907 & Significant \\
\hline
\end{tabular}

contrast to our study where although the prevalence of OAD was high, no association with a number of coronary vessel involvement was seen. Noninclusion of the smoker in our study might be the reason for this disparity.

In our study, $47.4 \%$ of the females had OAD, while only $14.8 \%$ of the males were detected to have airflow obstruction in spirometry. The association was found to be significant as $P<0.05$. This finding was in contrast to the study done by Ullah et al.$^{[18]}$ In their study, out of 151 patients, $57(37.7 \%)$ were found to have COPD, in which 39 (68.42\%) were male and 18 (31.57\%) were female. Similarly, Liang et al. found significantly more number of males having COPD in CAD ${ }^{[8]}$ However, they included smokers in their study who were mostly male. All the nonsmokers were female. In our study, only nonsmokers were included from the study.

\section{Conclusion}

Spirometry is an inexpensive investigation which can be done easily at the bedside. It should be done routinely in all the patients with CAD along with the screening of other risk factors such as hypertension, diabetes mellitus, and dyslipidemia so that both CAD and OAD can be managed adequately with better outcomes. Spirometry indices are good in assessing the prevalence of OAD in nonsmoker patients with catheter-diagnosed CAD. Our study failed to establish any relationship between the severity of CAD and OAD. Although some studies done previously showed more chances of severe airway obstruction in patients with more severe CAD, larger randomized controlled trials/prospective studies are needed.

There were few limitations in our study. This study had a relatively small sample size which leads to weak correlation between some variables and discrepancies between our study and previous studies. In our study, only CAD patients who underwent coronary angiography were included due to which patients without significant obstruction of coronary vessels were excluded.

\section{Financial support and sponsorship} Nil.

\section{Conflicts of interest}

There are no conflicts of interest.

\section{RefEREnCES}

1. Patil VC, Pujari BN, Patil HV, Munjal A, Agrawal V. Prevalence of obstructive airway disease by spirometric indices in non-smoker subjects with IHD and HTN. Lung India 2012;29:241-7.

2. Boschetto P, Beghé B, Fabbri LM, Ceconi C. Link between chronic obstructive pulmonary disease and coronary artery disease: Implication for clinical practice. Respirology 2012;17:422-31.

3. Campo G, Pavasini R, Malagù M, Mascetti S, Biscaglia S, Ceconi C, et al. Chronic obstructive pulmonary disease and ischemic heart disease comorbidity: Overview of mechanisms and clinical management. Cardiovasc Drugs Ther 2015;29:147-57.

4. Salisbury AC, Reid KJ, Spertus JA. Impact of chronic obstructive pulmonary disease on post-myocardial infarction outcomes. Am J Cardiol 2007;99:636-41.

5. Behar S, Panosh A, Reicher-Reiss H, Zion M, Schlesinger Z, Goldbourt U. Prevalence and prognosis of chronic obstructive pulmonary disease among 5,839 consecutive patients with acute myocardial infarction. SPRINT study group. Am J Med 1992;93:637-41.

6. Jindal SK, Aggarwal AN, Gupta D. A review of population studies from India to estimate national burden of chronic obstructive pulmonary disease and its association with smoking. Indian J Chest Dis Allied Sci 2001;43:139-47.

7. McKay AJ, Mahesh PA, Fordham JZ, Majeed A. Prevalence of COPD in India: A systematic review. Prim Care Respir J 2012;21:313-21.

8. Liang BM, Xu ZB, Yi Q, Ou XM, Feng YL. Association of chronic obstructive pulmonary disease with coronary artery disease. Chin Med J (Engl) 2013;126:3205-8.

9. Bursi F, Vassallo R, Weston SA, Killian JM, Roger VL. Chronic obstructive pulmonary disease after myocardial infarction in the community. Am Heart J 2010;160:95-101.

10. Berger JS, Sanborn TA, Sherman W, Brown DL. Effect of chronic obstructive pulmonary disease on survival of patients with coronary heart disease having percutaneous coronary intervention. Am J Cardiol 2004;94:649-51.

11. Selvaraj CL, Gurm HS, Gupta R, Ellis SG, Bhatt DL. Chronic obstructive pulmonary disease as a predictor of mortality in patients undergoing percutaneous coronary intervention. Am J Cardiol 2005;96:756-9.

12. Kohansal R, Martinez-Camblor P, Agustí A, Buist AS, Mannino DM, Soriano JB. The natural history of chronic airflow obstruction revisited: 
Agrawal, et al.: COPD in coronary artery disease patients

An analysis of the Framingham offspring cohort. Am J Respir Crit Care Med 2009;180:3-10.

13. Engström G, Wollmer P, Valind S, Hedblad B, Janzon L. Blood pressure increase between 55 and 68 years of age is inversely related to lung function: Longitudinal results from the cohort study 'men born in 1914'. J Hypertens 2001;19:1203-8.

14. Das S, Mukherjee S, Kundu S, Mukherjee D, Ghoshal AG, Paul D. Presence and severity of COPD among patients attending cardiology OPD of a tertiary healthcare centre. J Indian Med Assoc 2010;108:406-9.

15. Soriano JB, Rigo F, Guerrero D, Yañez A, Forteza JF, Frontera G, et al. High prevalence of undiagnosed airflow limitation in patients with cardiovascular disease. Chest 2010;137:333-40.

16. Almagro P, Lapuente A, Pareja J, Yun S, Garcia ME, Padilla F, et al. Underdiagnosis and prognosis of chronic obstructive pulmonary disease after percutaneous coronary intervention: A prospective study. Int J Chron Obstruct Pulmon Dis 2015;10:1353-61.

17. Ahmed AH, Yagoub TE, Muthana F. Prevalence of chronic obstructive pulmonary disease in patients with catheter-diagnosed coronary artery disease. Ann Thorac Med 2009;4:91-2.

18. Ullah R, Salam S, Ghaffar T, Muhammad R, Khan I. Frequency of undiagnosed chronic obstructive pulmonary disease in patients with coronary artery disease. J Ayub Med Coll Abbottabad 2017;29:285-8. 